\title{
Properties of Soldering Cu/Fe Alloy Produced by Powder Metallurgy
}

\author{
Hidekazu Sueyoshi ${ }^{1}$, Ryosuke Ishii ${ }^{1, * 1}$, Hisayoshi Fukudome ${ }^{1, * 2}$, Shinji Mizokuchi ${ }^{2}$, \\ Toshio Wakabayashi ${ }^{2}$ and Kazuya Saikusa ${ }^{2}$ \\ ${ }^{1}$ Graduate School of Science and Engineering, Kagoshima University, Kagoshima 890-0065, Japan \\ ${ }^{2}$ Techno Center, JAPAN UNIX Co. Ltd., Kamimashikigun, Kumamoto 861-2202, Japan
}

In order to develop an advanced soldering material, the $\mathrm{Cu} / \mathrm{Fe}$ alloys were produced by using powder metallurgy and the soldering properties were examined. Thermal conductivity of $\mathrm{Cu} / \mathrm{Fe}$ alloy decreased with the increase in the volume fraction of pores, while it increased with the increase in the volume fraction of $\mathrm{Cu}$ particles. Wettability of $\mathrm{Cu} / \mathrm{Fe}$ alloy was better than that of conventional $\mathrm{Fe}$ plating. Comparing the consumption amounts under the same wettability, the amount of $\mathrm{Cu} / \mathrm{Fe}$ alloy consumed was smaller than that of Fe plating consumed. [doi:10.2320/matertrans.MRA2008112]

(Received April 4, 2008; Accepted October 3, 2008; Published November 12, 2008)

Keywords: lead-free solder, copper/iron alloy, powder metallurgy, wettability, thermal conductivity

\section{Introduction}

The core of a conventional soldering iron for a soldering robot is made of $\mathrm{Cu}$, which has a high thermal conductivity, and its surface is covered by Fe plating. Once the whole of Fe plating is consumed during soldering, resulting in the loss of function of the soldering iron. ${ }^{1)}$ Nowadays, due to the environment concern that $\mathrm{Pb}$ is harmful to human health, conventional $\mathrm{Sn}-\mathrm{Pb}$ soldering has been switched into $\mathrm{Pb}$-free soldering in electronic packaging. ${ }^{2-4)}$ Because the practically used $\mathrm{Pb}$-free solder ( $\mathrm{Sn}-\mathrm{Ag}-\mathrm{Cu}$ system) contains a large amount of Sn and has a high melting point compared with the conventional $\mathrm{Sn}-\mathrm{Pb}$ eutectic solder, the use of $\mathrm{Pb}$-free solder causes a significant increase in the consumption of the soldering iron, resulting in an increase in the number of times which the soldering iron is changed and a reduction in production efficiency owing to production discontinuouce. However, there are few reports regarding new soldering materials which may be used as an alternate for soldering iron.

In the present study, in order to develop an advanced soldering material, $\mathrm{Cu} / \mathrm{Fe}$ alloys were prepared by using powder metallurgy and density, thermal conductivity, wettability, reactability between fused $\mathrm{Pb}$-free solder and $\mathrm{Cu} / \mathrm{Fe}$ alloy and consumption of soldering $\mathrm{Cu} / \mathrm{Fe}$ alloy were investigated.

\section{Experimental Procedure}

High purity carbonyl Fe powder (Mitsuwa Chemical Co. Ltd.: Fe; 99.5 mass\%, maximum particle diameter; $5 \mu \mathrm{m}$, mean particle diameter; $3.3 \mu \mathrm{m}$ ) and high purity $\mathrm{Cu}$ powders $(\mathrm{Cu} ; 99.8$ mass \%, symbol 10Cu: maximum particle diameter; $10 \mu \mathrm{m}$, mean particle diameter; $6.5 \mu \mathrm{m}$, symbol $45 \mathrm{Cu}$ : maximum particle diameter; $45 \mu \mathrm{m}$, mean particle diameter; $18.3 \mu \mathrm{m}$, and symbol 100Cu: maximum particle diameter;

\footnotetext{
${ }^{* 1}$ Graduate Student, Kagoshima University

${ }^{* 2}$ Graduate Student, Kagoshima University. Present address: Nakayama Steel Co. Ltd.
}

$100 \mu \mathrm{m}$, mean particle diameter; $72.8 \mu \mathrm{m})$ were used. Figure 1 shows secondary electron (SE) images of powders used. All the powders are spherical.

The $\mathrm{Cu} / \mathrm{Fe}$ powders having various $\mathrm{Cu}$ volume fractions $(0,4.5,8.9,18.1$ and $27.5 \mathrm{vol} \%)$ were compacted under an uni-axial pressure of $88.4 \mathrm{MPa}$, followed by sintering at $1223 \mathrm{~K}$ for $10 \mathrm{~h}$ in vacuum $(0.1 \mathrm{~Pa})$. The density of sintered compact was measured by Archimedes method (Alfa Mirage Co. Ltd.: MD-300S). Thermal conductivity of sintered compact disk having a diameter of $10 \mathrm{~mm}$ and $1.5 \mathrm{~mm}$ thickness was measured by laser flash method (Rigaku Co. Ltd.: LF-TCM).

$\mathrm{Pb}$-free solder of the $\mathrm{Sn}-3.0 \mathrm{Ag}-0.5 \mathrm{Cu}$ system including a flux (Senju Kinzoku Co. Ltd.: ECO SOLDER RMA02P3M705-1.0) was used. The fused solder was held on the surface of sintered compact at $653 \mathrm{~K}$ for various times to examine reactability between $\mathrm{Pb}$-free solder and $\mathrm{Cu} / \mathrm{Fe}$ alloy. Then the microstructure of the longitudinal section of sintered compact was examined using an electron probe micro-analyzer (EPMA). The fused solder $(0.03 \mathrm{~g})$ was held at $653 \mathrm{~K}$ on the surface of sintered compact in air to measure contact angle. The consumption of soldering $\mathrm{Cu} / \mathrm{Fe}$ alloy was examined using a soldering robot (Japan Unix Co. Ltd.: UNIX-412). ${ }^{1)}$ In the consumption test, soldering $\mathrm{Cu} / \mathrm{Fe}$ alloy was heated to testing temperature, and then maintained till the steady state in which no change in temperature achieved. Thereafter, $\mathrm{Pb}$-free solder of $10.5 \mathrm{~mm}$ length was supplied to the center of the soldering $\mathrm{Cu} / \mathrm{Fe}$ alloy automatically and then held for $7.25 \mathrm{~s}$, followed by compressed air cleaning at the center of soldering $\mathrm{Cu} / \mathrm{Fe}$ alloy (angle of air cleaning nozzle to soldering $\mathrm{Cu} / \mathrm{Fe}$ alloy: $\pi / 2$, air pressure: $0.49 \mathrm{MPa}$, nozzle diameter: $1.5 \mathrm{~mm}$, blowing time: $0.3 \mathrm{~s}$ ). We designate the process from solder supply to compressed air cleaning as one cycle. The consumption test was carried out to 5000 cycles.

Figure 2 shows a schematic illustration of the longitudinal section of soldering $\mathrm{Cu} / \mathrm{Fe}$ alloy that the mixture of $\mathrm{Cu}$ and $\mathrm{Fe}$ powders was compacted under an uni-axial pressure of 88.4 MPa, followed by sintering at $1223 \mathrm{~K}$ for $10 \mathrm{~h}$ in vacuum $(0.1 \mathrm{~Pa})$. To prevent the spreading of fused solder, a $\mathrm{Cr}$ 

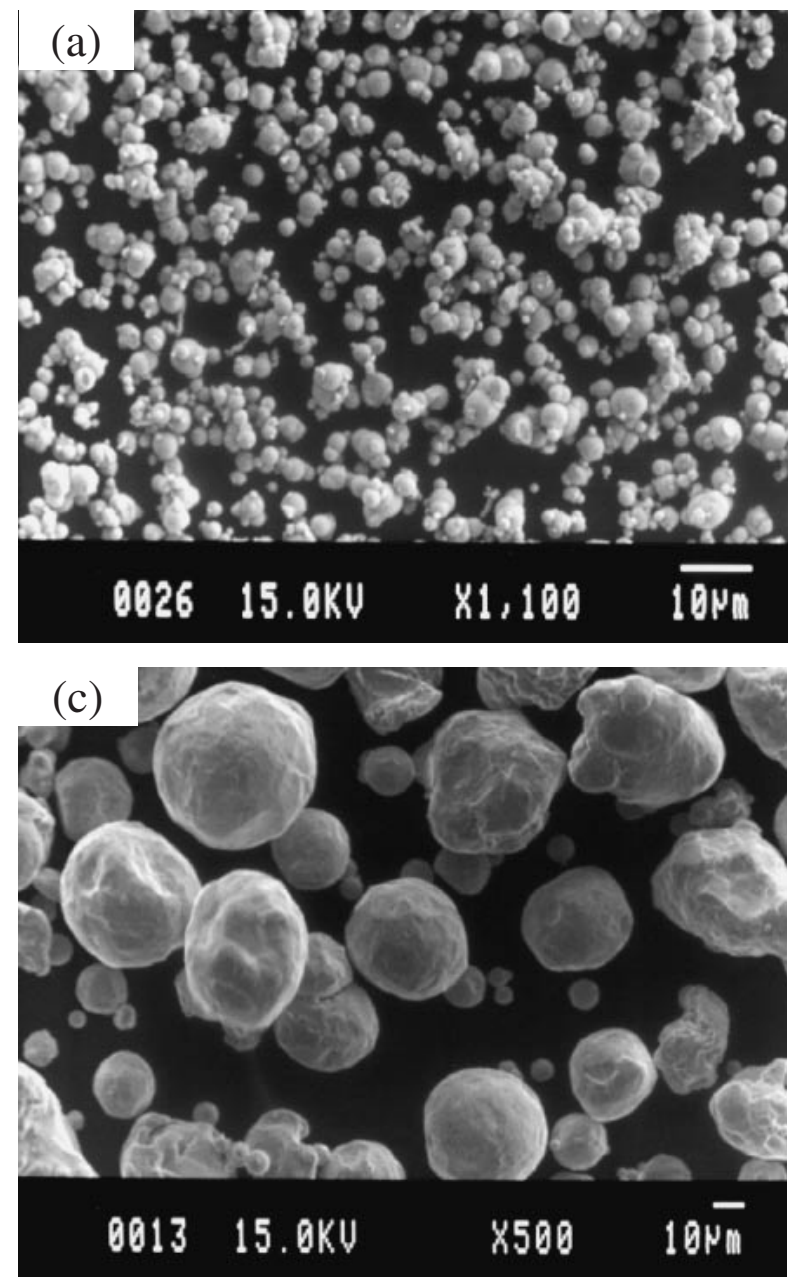

Fig. 1 SE images of powders used. (a) Fe, (b) $10 \mathrm{Cu}$, (c) $45 \mathrm{Cu}$ and (d) $100 \mathrm{Cu}$.

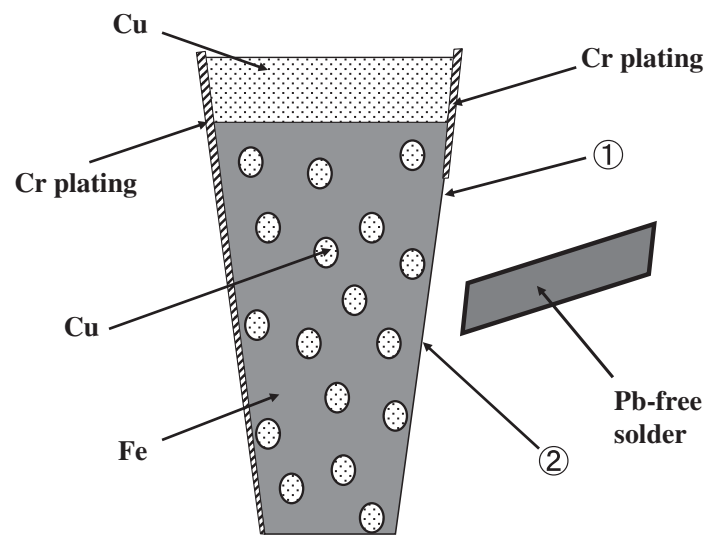

Fig. 2 Schematic illustration of the longitudinal section of soldering $\mathrm{Cu}$ / Fe alloy.

plating is applied on the upper and hind sides of the soldering $\mathrm{Cu} / \mathrm{Fe}$ alloy. The shape of every soldering $\mathrm{Cu} / \mathrm{Fe}$ alloy before the consumption test was measured using a projector. The shape of longitudinal section of soldering $\mathrm{Cu} / \mathrm{Fe}$ alloy after the consumption test was examined using EPMA (SE image). The consumption amount, which is the decrease in thickness of soldering $\mathrm{Cu} / \mathrm{Fe}$ alloy, was measured at positions (1) (near the $\mathrm{Cr}$ plating) and (2) (the center of the solder contact plane) in Fig. 2.
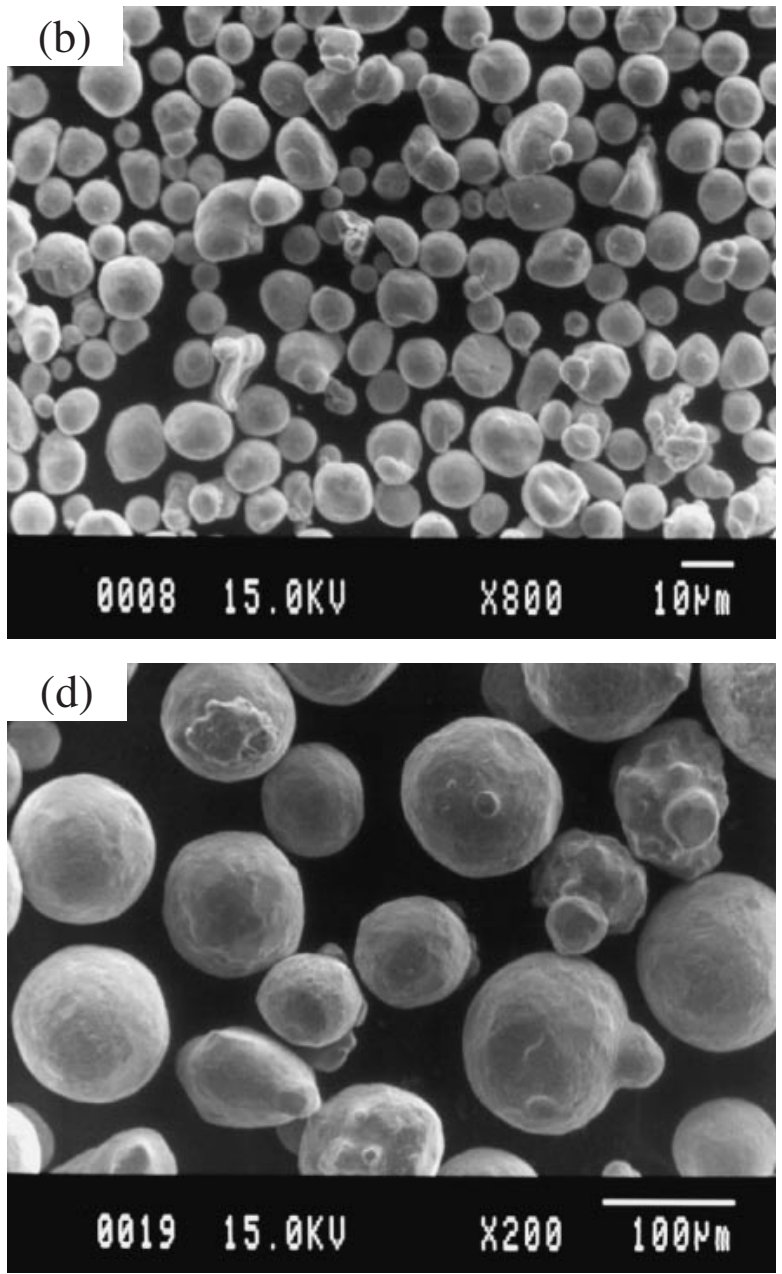

\section{Results and Discussion}

Figure 3 shows SE images of the longitudinal section of $\mathrm{Cu} / \mathrm{Fe}$ alloys. The white parts are $\mathrm{Cu}$ particles. In $10 \mathrm{Cu} / \mathrm{Fe}$ alloy (Fig. 3(a)), plastic deformation of $\mathrm{Cu}$ particles is observed. In $45 \mathrm{Cu} / \mathrm{Fe}$ alloy (Fig. 3(b), irregularity of the surface of $\mathrm{Cu}$ particles appears. These are because the plastic deformation of soft $\mathrm{Cu}$ particles due to hard Fe particles occurs during compaction. As shown in Figs. 3(a) and 3(b), a number of pores were observed. As shown in Fig. 3(c), uniform dispersion of $\mathrm{Cu}$ particles could be achieved even when $\mathrm{Cu}$ particles were very large.

Figure 4 shows the changes in density and relative density (the ratio of measured density to theoretical density calculated from the volume fraction of $\mathrm{Cu}$ particles) of sintered compact with the volume fraction of $\mathrm{Cu}$ particles. The density of sintered $\mathrm{Fe}$ is smaller than that of pure bulk Fe $\left(7.87 \mathrm{Mg} / \mathrm{m}^{3}\right) .{ }^{5)}$ Also the relative density of sintered $\mathrm{Fe}$ is smaller than 1 (full density). This is due to the presence of pores in the sintered $\mathrm{Fe}$. Because density of pure bulk $\mathrm{Cu}$ $\left(8.93 \mathrm{Mg} / \mathrm{m}^{3}\right)^{5)}$ is larger than that of pure bulk Fe, it is expected that density of $\mathrm{Cu} / \mathrm{Fe}$ alloy increases with the increase in the volume fraction of $\mathrm{Cu}$ particles. However, as shown in Fig. 4, the obtained results showed opposite behavior. Considering both the pores in sintered compact and the volume fraction of $\mathrm{Cu}$ particles, the density is given by 
(a)

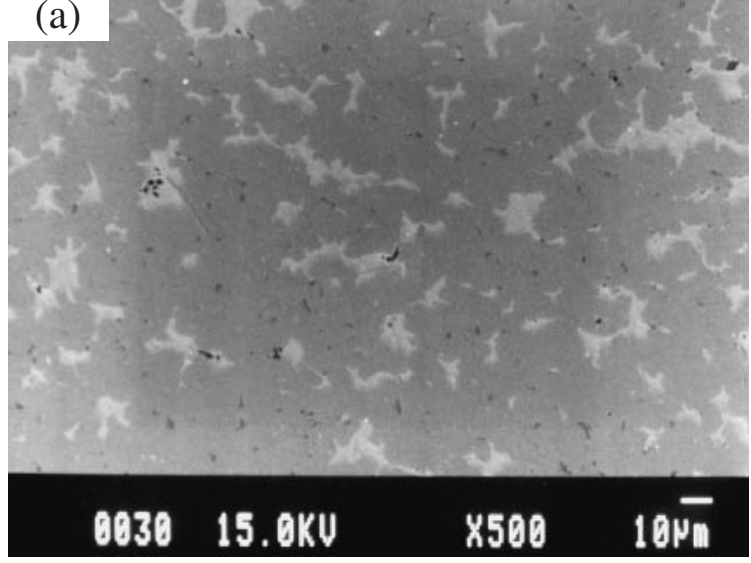

(b)
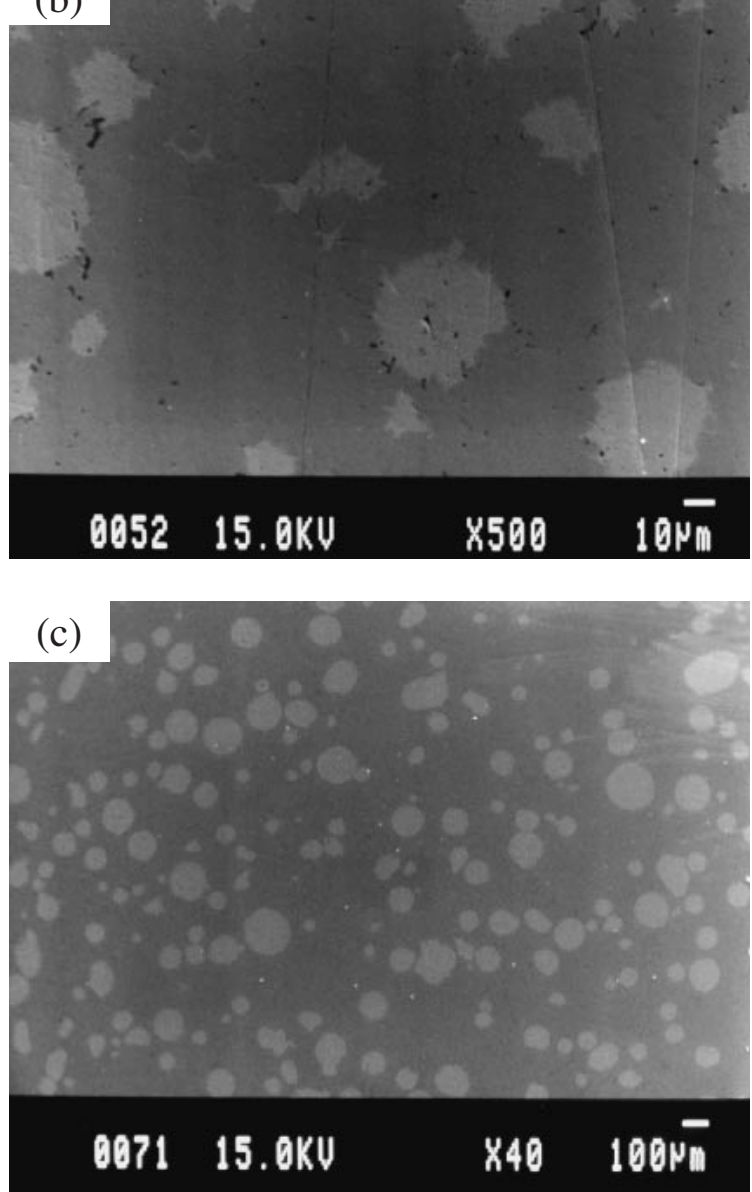

Fig. 3 SE images of the longitudinal section of $\mathrm{Cu}(27.5 \mathrm{vol} \%) / \mathrm{Fe}$ alloys. (a) $10 \mathrm{Cu} / \mathrm{Fe}$ alloy, (b) $45 \mathrm{Cu} / \mathrm{Fe}$ alloy and (c) $100 \mathrm{Cu} / \mathrm{Fe}$ alloy.

$$
\rho=\rho_{\mathrm{Fe}}\left(1-V_{\mathrm{p}}-V_{\mathrm{Cu}}\right)+\rho_{\mathrm{Cu}} V_{\mathrm{Cu}}
$$

where $\rho_{\mathrm{Fe}}, \rho_{\mathrm{Cu}}$ and $\rho$ is the density of pure bulk Fe, $\mathrm{Cu}$ and density of sintered compact, respectively, $V_{\mathrm{p}}$ is volume fraction of pores (1-relative density) and $V_{\mathrm{Cu}}$ is volume fraction of $\mathrm{Cu}$ particles.

Figure 5 shows the relationship between density calculated from eq. (1), $\rho_{\text {cal }}$, and measured density, $\rho_{\text {exp }}$. The values of $\rho_{\text {cal }}$ agree well with those of $\rho_{\text {exp }}$. Thus, density of sintered $\mathrm{Cu} / \mathrm{Fe}$ alloy depends on both the volume fraction of pores and the volume fraction of $\mathrm{Cu}$ particles.

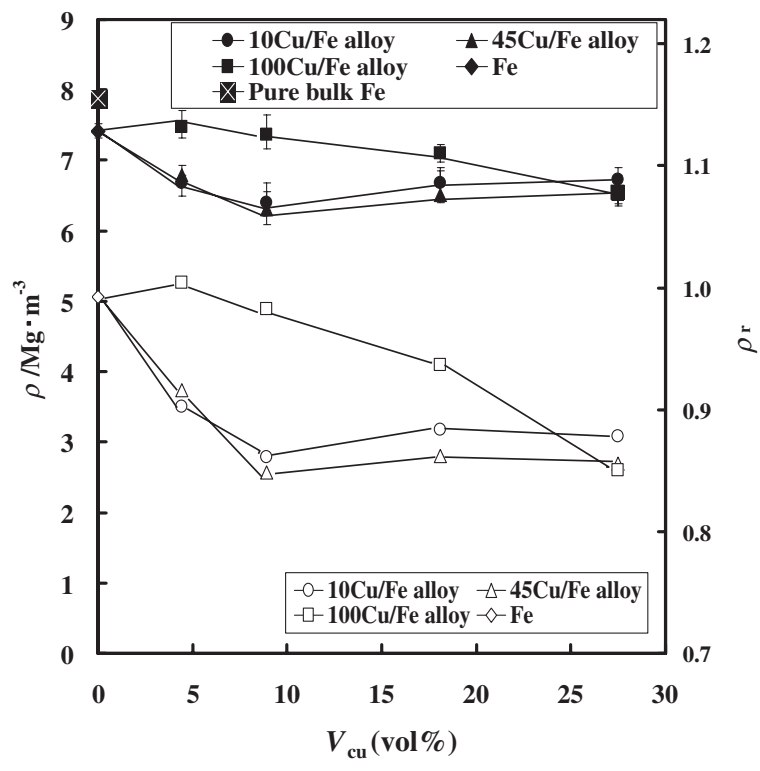

Fig. 4 Changes in density and relative density of sintered compact with the volume fraction of $\mathrm{Cu}$ particles.

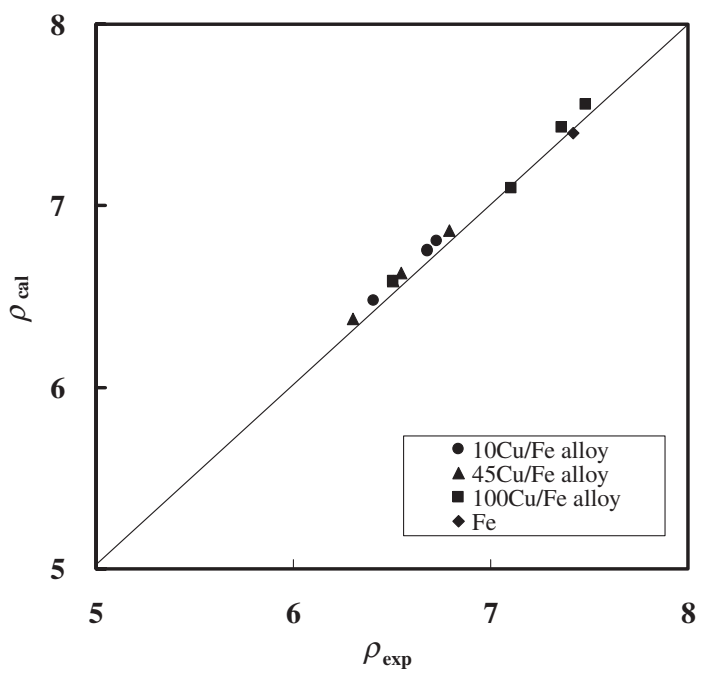

Fig. 5 Comparison between calculated density, $\rho_{\text {cal }}$, and measured one, $\rho_{\text {exp. }}$.

Figure 6 shows the relationship between thermal conductivity of sintered compact and the volume fraction of $\mathrm{Cu}$ particles. The thermal conductivity of sintered $\mathrm{Fe}$ is smaller than that of pure bulk Fe $(78.2 \mathrm{~W} /(\mathrm{m} \cdot \mathrm{K})){ }^{6}{ }^{6}$ This may be due to the presence of pores in sintered Fe. Since thermal conductivity of pure bulk $\mathrm{Cu}(397 \mathrm{~W} /(\mathrm{m} \cdot \mathrm{K}))^{6)}$ is larger than that of pure bulk Fe, it is expected that thermal conductivity of $\mathrm{Cu} / \mathrm{Fe}$ alloy increases as the volume fraction of $\mathrm{Cu}$ particles increases. However, as shown in Fig. 6, the obtained results showed opposite behavior. This suggests that $\kappa$ vary depending on both the pores and the $\mathrm{Cu}$ particles. From multi-regression analysis of thermal conductivity using the volume fractions of pores and $\mathrm{Cu}$ particles, thermal conductivity is given by

$$
\kappa=79.9-176 V_{\mathrm{p}}+172 V_{\mathrm{Cu}}^{2}
$$




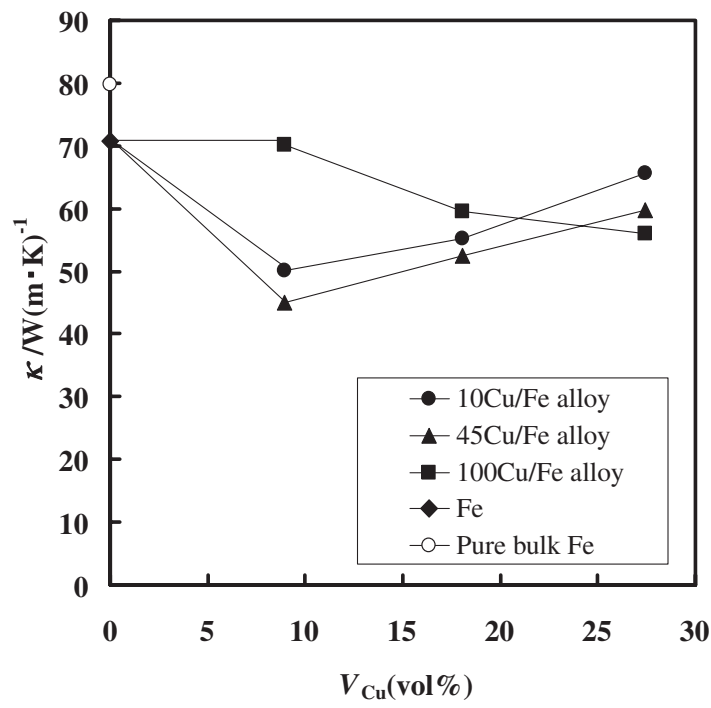

Fig. 6 Relationship between thermal conductivity of sintered compact and the volume fraction of $\mathrm{Cu}$ particles.

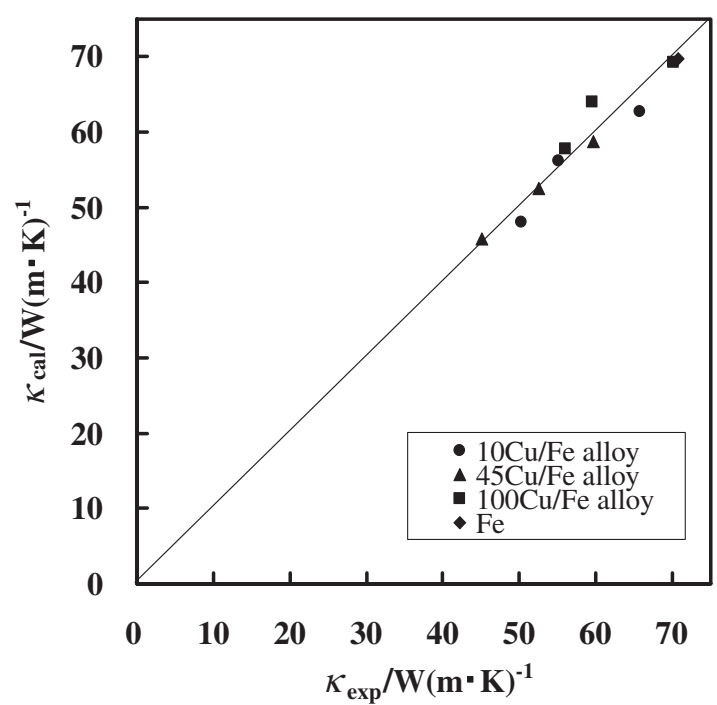

Fig. 7 Comparison between calculated thermal conductivity, $\kappa_{\mathrm{cal}}$, and measured one, $\kappa_{\text {exp }}$.

where $\kappa$ is thermal conductivity of sintered compact. Substituting $V_{\mathrm{p}}=0$ and $V_{\mathrm{Cu}}=0$ in eq. (2), we obtain $\kappa_{\mathrm{cal}}=79.9 \mathrm{~W} /(\mathrm{m} \cdot \mathrm{K})$. This value, which indicates thermal conductivity of pore-free sintered $\mathrm{Fe}$, is compatible with thermal conductivity of pure bulk Fe $(78.2 \mathrm{~W} /(\mathrm{m} \cdot \mathrm{K})) .{ }^{6}{ }^{\text {}}$

Figure 7 shows the relationship between thermal conductivity calculated from eq. (2), $\kappa_{\text {cal }}$, and measured one, $\kappa_{\text {exp }}$. The values of $\kappa_{\text {cal }}$ agree well with those of $\kappa_{\text {exp }}$. Thus, thermal conductivity of sintered $\mathrm{Cu} / \mathrm{Fe}$ alloy decreases with the increase in the volume fraction of pores, while it increases with the increase in the volume fraction of $\mathrm{Cu}$ particles. As shown in Fig. 6, the values of $\kappa$ at $V_{\mathrm{Cu}}=9 \mathrm{vol} \%$ in $10 \mathrm{Cu} / \mathrm{Fe}$ and $45 \mathrm{Cu} / \mathrm{Fe}$ alloys are smaller than that of sintered $\mathrm{Fe}$. This is because the decrease in $\kappa$ due to large $V_{\mathrm{p}}$ (Fig. 4 ) is superior to the increase in $\kappa$ due to small $V_{\mathrm{Cu}}$. When $V_{\mathrm{Cu}}$ exceeds $9 \mathrm{vol} \%$, the values of $\kappa$ increase with increasing $V_{\mathrm{Cu}}$. This is because $V_{\mathrm{p}}$ is almost unchanged by varying $V_{\mathrm{Cu}}$ (Fig. 4), while $\kappa$ increases with increasing $V_{\mathrm{Cu}}$.
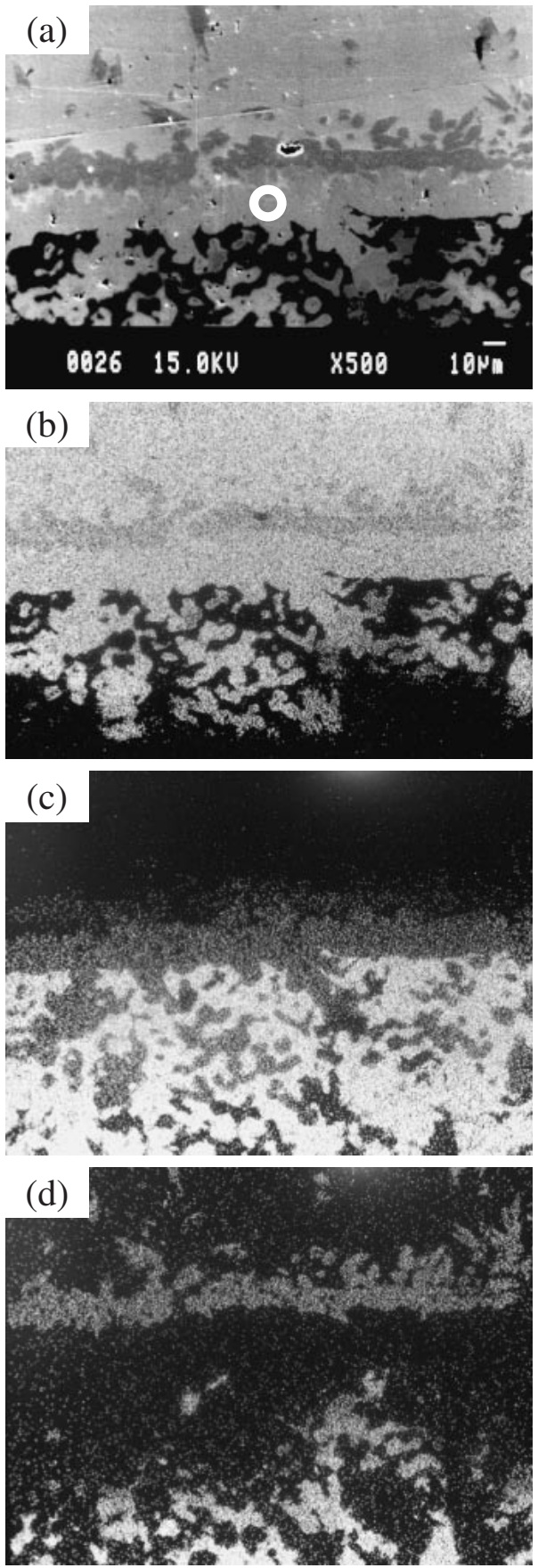

Fig. 8 EPMA analysis of the longitudinal section of $10 \mathrm{Cu}(27.5 \mathrm{vol} \%) / \mathrm{Fe}$ alloy that fused solder was held on the surface at $653 \mathrm{~K}$ for $24 \mathrm{~h}$. (a) SE image, (b) Sn K $\alpha$-ray image, (c) $\mathrm{Fe} \mathrm{K} \alpha$-ray image and (d) $\mathrm{Cu} \mathrm{K} \alpha$-ray image.

Figure 8 shows EPMA analysis of the longitudinal section of $10 \mathrm{Cu}(27.5 \mathrm{vol} \%) / \mathrm{Fe}$ alloy when fused solder was held on the surface at $653 \mathrm{~K}$ for $24 \mathrm{~h}$. In SE image, the upper part is solder, the lower part is $\mathrm{Cu} / \mathrm{Fe}$ alloy and the middle part is reaction layer. It is found that the reaction layer consists of two different layers. The result of EPMA quantitative analysis (point analysis) of the encircled area (Fig. 8(a)) in the lower reaction layer indicated $\mathrm{Cu}: \mathrm{Fe}: \mathrm{Sn}=0.98$ : $32.01: 67.01 \mathrm{in}$ at $\%$. This suggests that the lower reaction layer consists of $\mathrm{FeSn}_{2}$. The formation of $\mathrm{FeSn}_{2}$ during soldering was also detected in case of Fe plating. ${ }^{1)}$ As shown in area analysis, few $\mathrm{Cu}$ is found in $\mathrm{Cu} / \mathrm{Fe}$ alloy near the 

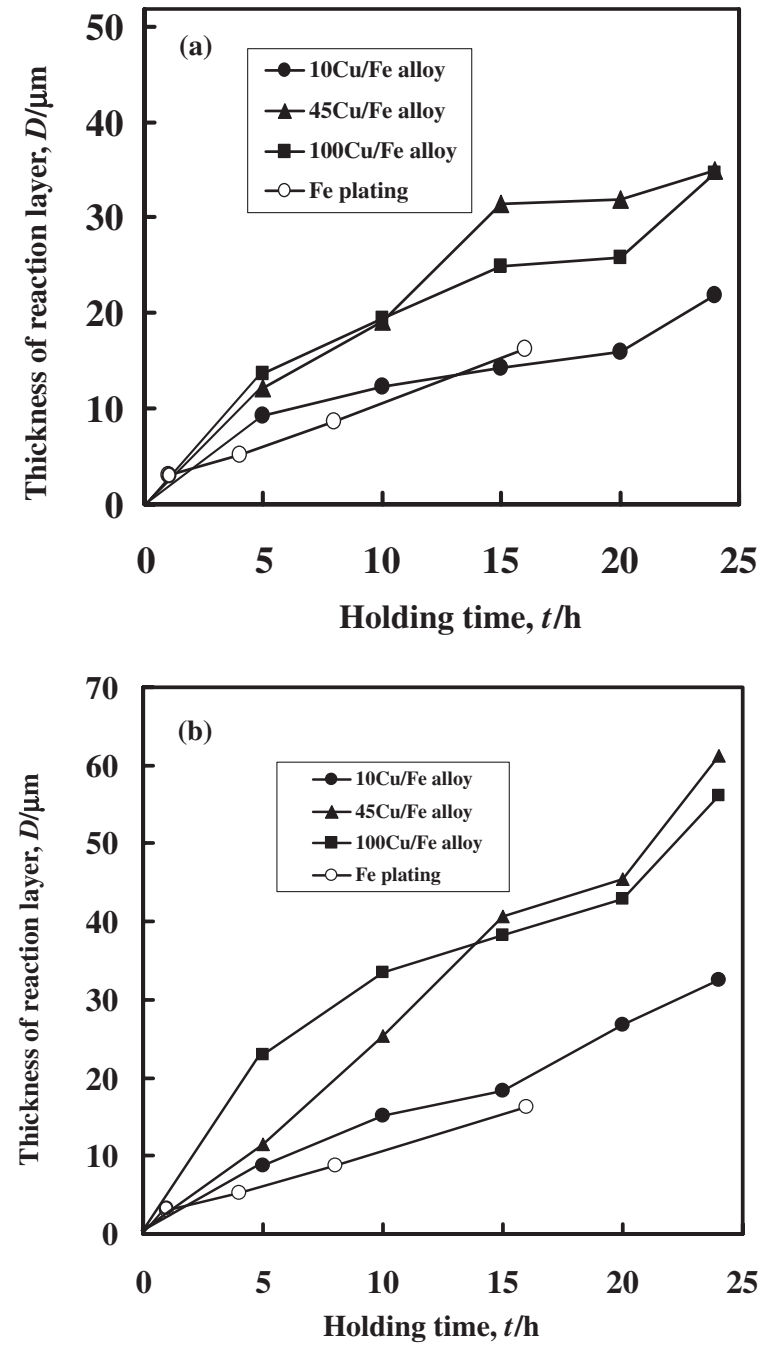

Fig. 9 Relationship between the thickness of reaction layer in $\mathrm{Cu}(27.5$ vol\%)/Fe alloys and holding time. (a) lower reaction layer $\left(\mathrm{FeSn}_{2}\right)$ and (b) all reaction layer.

reaction layer though $\mathrm{Cu}$ is detected in $\mathrm{Cu} / \mathrm{Fe}$ alloy a little way off the reaction layer. On the other hand, Fe still remaines in $\mathrm{Cu} / \mathrm{Fe}$ alloy near the reaction layer and $\mathrm{FeSn}_{2}$ is detected at $\mathrm{Cu}$-poor region (once a $\mathrm{Cu}$ particle). In accordance with the $\mathrm{Fe}-\mathrm{Sn}$ equilibrium phase diagram, ${ }^{7)} \mathrm{Fe}$ undissolves within the liquid $\mathrm{Sn}$ at $653 \mathrm{~K}$ but $\mathrm{FeSn}_{2}$ is formed. In accordance with the $\mathrm{Cu}-\mathrm{Sn}$ equilibrium phase diagram, ${ }^{8)} \mathrm{Cu}$ dissolves into the liquid $\mathrm{Sn}$ at $653 \mathrm{~K}$. As $\mathrm{Cu}$ content in liquid $\mathrm{Sn}$ increases, $\mathrm{Cu}-\mathrm{Sn}$ compound crystallizes partially. These results suggest that preferential dissolution of $\mathrm{Cu}$ in $\mathrm{Cu} / \mathrm{Fe}$ alloy into $\mathrm{Sn}$ in fused solder occurs, followed by the reaction between $\mathrm{Sn}$ and $\mathrm{Fe}$. The upper layer $(\mathrm{Cu}-\mathrm{Sn}$ compound) may be formed by reaction between $\mathrm{Sn}$ and $\mathrm{Cu}$ which is swept away from the lower reaction layer on the process of the formation of $\mathrm{FeSn}_{2}$.

Figure 9 shows the relationship between the thickness of reaction layer in $10 \mathrm{Cu}(27.5 \mathrm{vol} \%) / \mathrm{Fe}$ alloys and holding time at $653 \mathrm{~K}$. The results of conventional Fe plating are also plotted in Fig. 9. ${ }^{1)}$ As shown in Fig. 9(a), the thickness of lower reaction layer $\left(\mathrm{FeSn}_{2}\right)$ of $10 \mathrm{Cu} / \mathrm{Fe}$ alloy having small $\mathrm{Cu}$ particles is almost equivalent to that of $\mathrm{Fe}$ plating. However, when a diameter of $\mathrm{Cu}$ particles is large. As shown in Fig. 9(b), the changes in thickness of all reaction layer

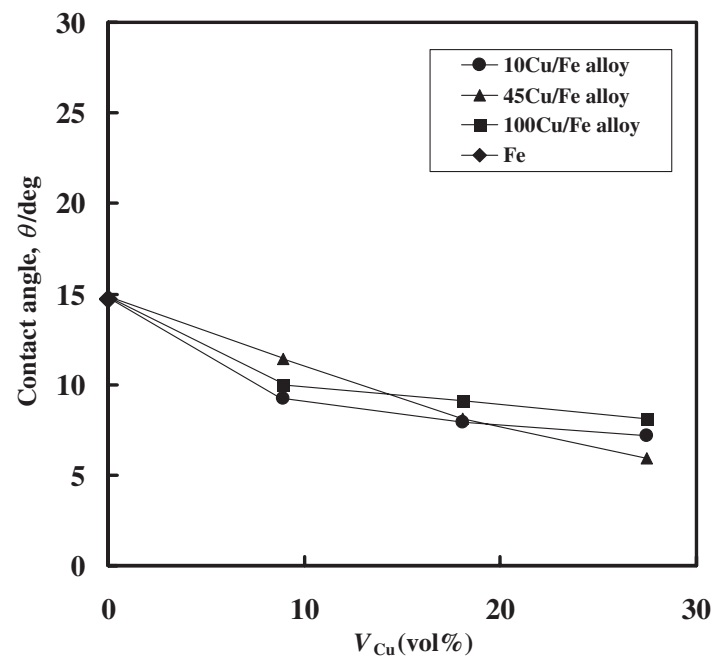

Fig. 10 Relationship between contact angle for sintered compact and the volume fraction of $\mathrm{Cu}$ particles.

(lower reaction layer $\left(\mathrm{FeSn}_{2}\right)+$ upper reaction layer $(\mathrm{Cu}-\mathrm{Sn}$ compound)) are similar to those of lower reaction layer (Fig. 9(a)). As mentioned above, the thickness of lower reaction layer increases when a diameter of $\mathrm{Cu}$ particles is large. This is because the growth of lower reaction layer is enhanced by the behavior that the formation of large amounts of $\mathrm{FeSn}_{2}$ occurs at $\mathrm{Cu}$-poor region (once a $\mathrm{Cu}$ particle) below lower reaction layer (Fig. 8), too.

Figure 10 shows the relationship between contact angle for sintered compact and the volume fraction of $\mathrm{Cu}$ particles. Contact angle decreases with the increase in the volume fraction of $\mathrm{Cu}$ particles. This is because wettability of $\mathrm{Sn} / \mathrm{Cu}$ system is better than that of $\mathrm{Sn} / \mathrm{Fe}$ system. There is no influence of $\mathrm{Cu}$ particle size on contact angle. This is because the area fraction of $\mathrm{Cu}$ in the contact area is almost equal independing on $\mathrm{Cu}$ particle size. It is thought that $\mathrm{Cu}$ particle size dependence of the reaction layer thickness (Fig. 9) relate to the reaction toward the interior rather than on the surface.

Figure 11 shows the relationship between contact angle and fusing temperature. Contact angle decreases as fusing temperature is high. Comparing these contact angles at the same fusing temperature, contact angle of $10 \mathrm{Cu}(27.5 \mathrm{vol} \%) /$ $\mathrm{Fe}$ alloy is lower than that of Fe plating. It is found from Fig. 11 that contact angle equivalent to that of Fe plating at $653 \mathrm{~K}$ can be achieved at lower temperature $(616 \mathrm{~K})$ in $10 \mathrm{Cu} /$ Fe alloy.

Figure 12 shows the shape (SE image) of the longitudinal section of soldering $\mathrm{Cu} / \mathrm{Fe}$ alloy after the consumption test. The consumption amount at position (1) in Fig. 2 is larger than that at the position (2). This is because the reaction is promoted by the retained solder, which cannot be blown away during compressed air cleaning. The consumption at the bottom of $\mathrm{Cu} / \mathrm{Fe}$ alloy is also observed. These phenomena are similar to those of Fe plating. ${ }^{1)}$

Figure 13 shows the relationship between the amount of soldering $\mathrm{Cu} / \mathrm{Fe}$ alloy consumed and temperature of consumption test. The results of Fe plating are also plotted in Fig. 13. ${ }^{1)}$ The symbols (1) and (2) in Fig. 13 correspond to the positions (1) and (2) in Fig. 2, respectively. Under the same temperature, the amount of $\mathrm{Cu} / \mathrm{Fe}$ alloy consumed is larger 


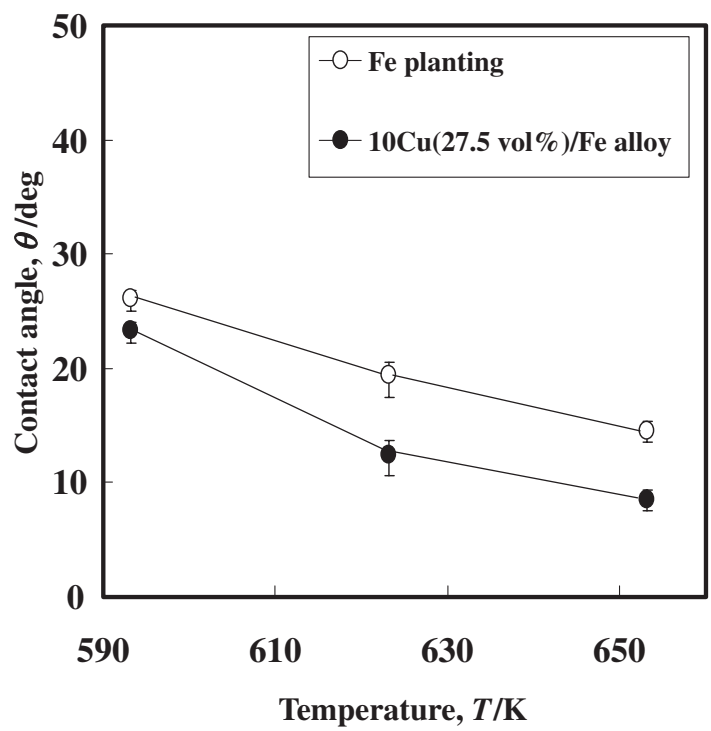

Fig. 11 Relationship between contact angle and fusing temperature.

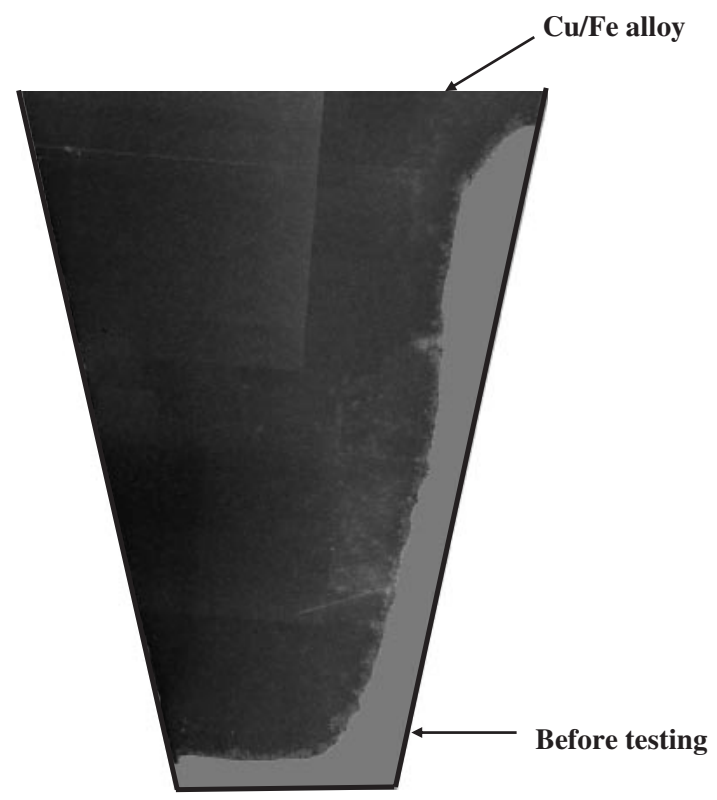

Fig. 12 Shape of the longitudinal section of soldering $\mathrm{Cu} / \mathrm{Fe}$ alloy after the consumption test.

than that of Fe plating consumed. However comparing the consumption amounts under the same wettability, the amount of $\mathrm{Cu} / \mathrm{Fe}$ alloy consumed is smaller than that of $\mathrm{Fe}$ plating consumed. Once the whole of Fe plating is consumed by soldering, resulting in the loss of function of the soldering iron. The increases in the number of exchanging the soldering iron and reconditioning time brings about a reduction in production. However, in case of soldering $\mathrm{Cu} / \mathrm{Fe}$ alloy shown in Fig. 2, it is possible for $\mathrm{Cu} / \mathrm{Fe}$ alloy to use for a long time till the whole of $\mathrm{Cu} / \mathrm{Fe}$ alloy is consumed, resulting in the decreases in the exchanging number and reconditioning time. This brings about an increase in production efficiency.

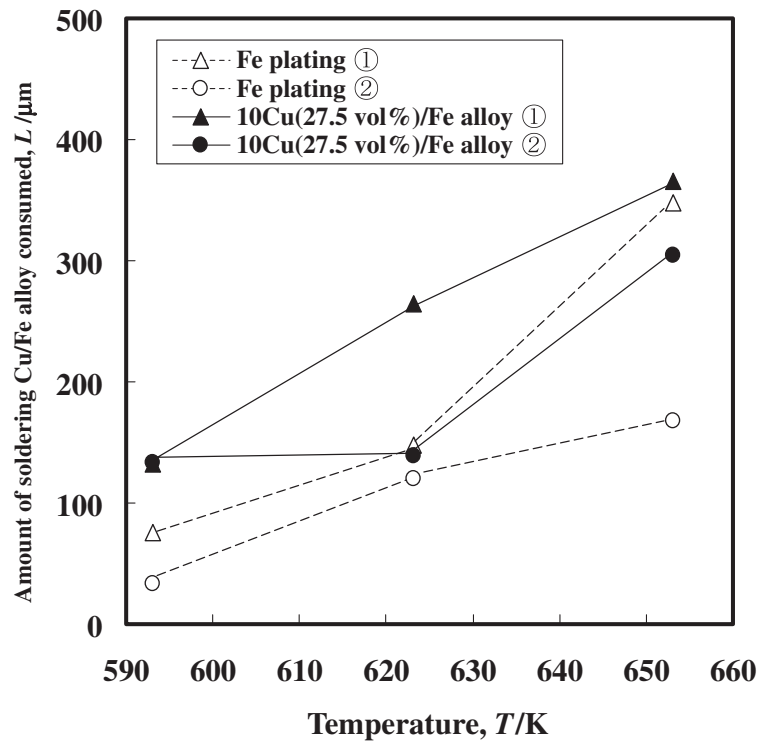

Fig. 13 Relationship between the amount of soldering $\mathrm{Cu} / \mathrm{Fe}$ alloy consumed and temperature of consumption test.

\section{Conclusions}

In order to develop an advanced soldering material, the $\mathrm{Cu} / \mathrm{Fe}$ alloys were produced by using powder metallurgy and its density, thermal conductivity, wettability, reactability between $\mathrm{Pb}$-free solder and $\mathrm{Cu} / \mathrm{Fe}$ alloys and consumption of soldering $\mathrm{Cu} / \mathrm{Fe}$ alloys were examined. The results obtained are as follows.

(1) Thermal conductivity of $\mathrm{Cu} / \mathrm{Fe}$ alloy decreased with the increase in the volume fraction of pores, while it increased with the increase in the volume fraction of $\mathrm{Cu}$ particles.

(2) Wettability of $\mathrm{Cu} / \mathrm{Fe}$ alloys was better than that of conventional Fe plating.

(3) Under the same soldering temperature, the amount of $\mathrm{Cu} / \mathrm{Fe}$ alloy consumed was larger than that of $\mathrm{Fe}$ plating consumed. However, comparing the consumption amounts under the same wettability, the amount of $\mathrm{Cu} / \mathrm{Fe}$ alloy consumed was smaller than that of $\mathrm{Fe}$ plating consumed.

\section{REFERENCES}

1) H. Sueyoshi, H. Odo, S. Mizokuchi, S. Abe and K. Saikusa: Mater. Trans. 47 (2006) 1221-1226.

2) K. Suganuma: Materia Japan 38 (1999) 919

3) T. Suga: Materia Japan 38 (1999) 920-922.

4) T. Nishimura: Materia Japan 43 (2004) 651-654.

5) Japan Inst. Metals: A Data Book on Metals (Maruzen, Tokyo, 2007) p. 10.

6) Japan Inst. Metals: A Data Book on Metals (Maruzen, Tokyo, 2007) p. 11.

7) ASM International: ASM Handbook Vol. 3 Alloy Phase Diagrams, (ASM International, Ohio, 1992) p. 2.203.

8) ASM International: ASM Handbook Vol. 3 Alloy Phase Diagrams, (ASM International, Ohio, 1992) p. 2.178. 